\title{
Энергетическая эфффективность спекания технической керамики в микроволновом поле
}

\author{
И. Л. Бошкова ${ }^{1}$, Н. В. Волгушева ${ }^{2}$, Н. А. Колесниченко \\ Одесская национальная академия пищевых технологий, ул. Канатная, 112, 65029, Одесса, Украина \\ e-mail: ${ }^{1}$ ira_boshkova@mail.ru, ${ }^{2}$ n-volgusheva@mail.ru, ${ }^{3}$ kolesnychenko.natalia@yandex.ua \\ ORCID: ${ }^{1}$ http://orcid.org/0000-0001-5989-9223, ${ }^{2}$ http://orcid.org/0000-0002-9984-6502, ${ }^{3}$ http://orcid.org/0000-0002-2851-8050
}

\begin{abstract}
Технологический процесс спекания в микроволновом поле дает возможность получения материалов с улучшенными по сравнению с существующими эксплуатационными и функциональными свойствами. Представлена оценка энергетической эффрективности микроволновой технологии спекания на примере производства керамических подложек. Для оценки использовались данные по технологическим параметрам спекания карбида кремния в печи фирмы MARUWA и по значениям скорости и продолжительности микроволнового нагрева. Установлено, что интенсивность спекания при переходе на микроволновую технологию существенно увеличивается, при этом затраты энергии значительно сокращаются.
\end{abstract}

Ключевые слова: Микроволновое поле; Энергоэффрективность; Спекание; Интенсификация; Керамика.

\section{Енергетична ефективність спікання технічної кераміки в мікрохвильовому полі}

\author{
І. Л. Бошкова, Н. В. Волгушева, Н. А. Колесніченко \\ Одеська національна академія харчових технологій, вул. Канатна, 112, 65029, Одеса, Україна
}

\begin{abstract}
Технологічний процес спікання в мікрохвильовому полі дає можливість одержання матеріалів з поліпшеними в порівнянні з існуючими експлуатаційними та функціональними властивостями. Представлена оцінка енергетичної ефективності мікрохвильової технології спікання на прикладі виробництва керамічних підложок. Для оцінки використовувалися дані за технологічними параметрами спікання карбіду кремнію в печі фірми MARUWA і за значеннями швидкості та тривалості мікрохвильового нагрівання. Встановлено, що інтенсивність спікання при переході на мікрохвильову технологію суттєво збільшується, при цьому витрати енергії значно скорочуються.
\end{abstract}

Ключові слова: Мікрохвильове поле; Енергоефективність; Спікання; Інтенсифікація; Кераміка.

DOI: http://dx.doi.org/10.15673/ret.v53i1.538

(C) The Author(s) 2017. This article is an open access publication

This work is licensed under the Creative Commons Attribution 4.0 International License (CC BY) http://creativecommons.org/licenses/by/4.0/

\section{1 Введение}

Технологический процесс спекания в микроволновом поле существенно отличается от классического конвективного. При комбинированном микроволновом (MB) нагреве тепло проходит с поверхности вглубь образца и одновременно генерируется внутри материалов, благодаря чему длительность процесса может быть значительно снижена. Сокращение времени может составлять для некоторых материалов до 80\% [1], или, как в ЦТС керамике (пьезокерамике), в 15-20 раз [2]. Другой важный аспект микроволнового спекания: установлено, что зерна спеченных образцов меньше по сравнению с зернами образцов, получаемых при применении классических методов [3, 4]. Отмечается положительное влияние микроволнового спекания на механические свойства материалов, как при спекании порошков $\mathrm{Al}_{2} \mathrm{O}_{3}, \mathrm{SiC}, \mathrm{ZrO}_{2}$ [3] и в ЦТС-керамике [5]. Методы микроволнового нагрева в настоящее время представляют значительный интерес для научных исследований с перспективой технологического освоения в ближайшем будущем [6]. Потенциал высокотемпературной микроволновой обработки продемонстрирован в таких областях, как спекание и соединение керамических материалов [7], неорганический синтез [8], создание композиционных [9] и функционально- 
градиентных [10] материалов, порошковая металлургия [11], отжиг имплантированных полупроводниковых структур [12]. Важное преимущество микроволнового нагрева обусловлено объемным поглощением микроволновой энергии в большинстве неметаллических материалов. При поглощении микроволновой энергии в объеме изделия отсутствует необходимость в передаче тепла за счет теплопроводности, как это происходит при нагреве излучением или конвективными потоками тепла в традиционных печах. Кроме того, мощность микроволнового источника может практически полностью использоваться на нагрев только обрабатываемого изделия, без необходимости нагревать массивные конструкции традиционных печей. Поэтому скорость нагрева микроволновым излучением может быть существенно выше, и это является одним из наиболее важных факторов во многих технологических процессах [13].

Высокие скорости нагрева обуславливают не только существенную экономию энергии и сокращение времени процессов, но, что зачастую более важно при создании высококачественных материалов, позволяют получать изделия с более мелкодисперсной и бездефектной микроструктурой и, как следствие, улучшенными функциональными свойствами [14].

Как показал анализ работ, посвященных данному направлению, не установлены области рационального применения МВ нагрева при спекании керамики и не приводятся количественные оценки энергетической эффективности В сравнении с традиционными технологиями. Целью работы являлось определение энергетической эффективности применения микроволнового нагрева при спекании керамики.

\section{2 Материалы для исследования}

В качестве исходного материала использовались порошки карбида кремния и оксида алюминия.

На основе оксида алюминия (метод микроволнового нагрева рационален только при добавлении поглощающих порошков) изготавливаются керамические диэлектрики (такие как изоляторы для вакуумных дугогасительных камер, твердые подложки).

Карбид кремния используется для изделий с высокими механическими характеристиками: керамические подшипники, инструмент, к примеру, насадки шлифовальные, пластины для электронной и оптоэлектронной промышленности.

В работе эффективность микроволнового нагрева при спекании рассматривается на примере изготовления керамических подложек. В качестве исходного сырья используются порошковые материалы: нитрида алюминия, оксида алюминия, нитрида кремния, оксида циркония, карбида кремния и другие. Керамические подложки применяются в электронной и электротехнической области промышленности (для производства монолитных интегральных схем, микросборок, термоэлектрических элементов Пельтье и пр.).
Исследование энергетической эффективности микроволнового спекания керамики на примере керамических подложек проведено на основании данных собственных экспериментов, которые позволили определить скорость нагрева в микроволновой камере, и полученных из литературных источников [12-14].

Применение микроволнового нагрева при спекании ограничивается видами изделий из технической керамики, размеры которых относительно должны быть невелики и глубина проникновения электромагнитной энергии в материал достаточна, чтобы обеспечивалась равномерность распределения температур по толщине.

Максимальные размеры выпускаемых подложек: 165X165 мм, толщина подложек - от 0,25 мм до 3,0 мм. Известно, что глубина проникновения микроволнового поля в керамическую массу на основе SiC составляет $\Delta=9,6$ мм. При такой толщине электромагнитное поле для рассматриваемых изделий будет равномерным. Форма подложек определяется потребителем.

\section{3 Результаты и обсуждение}

Для спекания керамических подложек IViTec предлагает конвейерную печь спекания LTCC серии FastFire II (США). Однако температурный уровень в этой печи не соответствует температуре спекания рассматриваемых порошков (для защиты от деформации рабочая температура ограничена $1150^{\circ} \mathrm{C}$ ): так, для спекания оксида алюминия $\mathrm{T}_{\mathrm{cn}}=1450^{\circ} \mathrm{C}$. Известна фирма MARUWA Integrating Ceramic Technologies, использующая печи камерного типа, в которых температура может достигать $1600^{\circ} \mathrm{C}$.

Максимальная скорость остывания - менее часа от температуры $1100^{\circ} \mathrm{C}$ до температуры ниже $100^{\circ} \mathrm{C}$. Подача холодного воздуха внутрь камеры во время выполнения термического цикла не производится.

Быстрый нагрев: макс. $60^{\circ} \mathrm{C} /$ мин $\left(1^{\circ} \mathrm{C} / \mathrm{c}\right)$, охлаждение от $1000^{\circ} \mathrm{C}$ до менее $100^{\circ} \mathrm{C}$ в течение 60 минут, при незагруженной печи.

Основные характеристики печи:

- максимальная длительность обжига - 240 мин.; - номинальная мощность при загрузке 50 кг - 60 кВт.

В расчете принималось, что толщина изделий $\delta=3 \cdot 10^{-3}$ м. При микроволновом нагреве: темп нагрева $1,7^{\circ} \mathrm{C} / \mathrm{c}$, рабочий уровень температур может быть снижен на $200^{\circ} \mathrm{C}$ (в соответствии с [13]), а длительность спекания в МВ поле составляет 60 мин [15]. Охлаждение начинается сразу после выключения магнетронов и определяется условиями взаимодействия с окружающей средой. В соответствии с зависимостями для неограниченной пластины [16], при естественной конвекции и для аналогичной загрузки камеры температура от $1000^{\circ} \mathrm{C}$ до $100^{\circ} \mathrm{C}$ снизиться в течение 520 с (8,7 мин), что сокращает длительность технологического процесса на этапе спекания. Сравнительная характеристика кинетики спекания для традиционного нагрева и микроволнового схематично изображена на рисунке 1. 


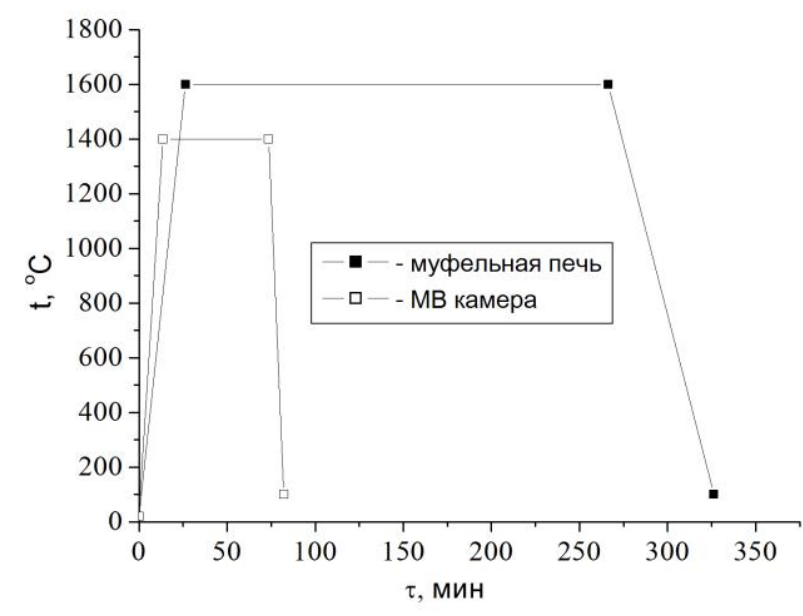

Рисунок 1 - Кинетика спекания керамических подложек при традиционном и микроволновом нагреве.

Длительность обжига керамических подложек в муфельной печи составляла 326,3 мин., в микроволновой камере - 82,2 мин. Таким образом, интенсивность процесса увеличилась в 4 раза.

Затраты энергии для муфельной печи составляли $Q$ $=0,959$ ГДж, для микроволновой камеры $Q=0,60$ ГДж. В расчете принималось, что КПД микроволновой камеры составляет $\eta_{\text {к }}=67 \%$, КПД магнетрона составляет $\eta_{м}=66 \%$, а муфельная печь является электрической. Тогда затраты энергии при переходе на МВ технологию на этапе обжига при производстве керамических подложек сократятся в 1,6 раза, а энергоэффективность при переходе на микроволновой нагрев выражается в экономии $37 \%$ электроэнергии. В расчете учитывалось время нагрева и выдержки изделий, т.е. 266,3 мин для муфельной печи и 73,5 мин для микроволновой камеры.

\section{4 Выводы}

Эффективность применения в промышленности микроволнового нагрева при спекании керамических подложек на основе порошка карбида кремния определяется сокращением длительности технологического цикла термообработки в четыре раза и снижения удельных энергозатрат на термообработку на $37 \%$.

\section{Литература}

1. Wielage B., Krause H., Leparoux S. Sintern von Keramik in einem gasbeheizten Ofen mit Mikrowellenunterstützung // Gaswärme International. - 2002. - № 51/8. - P. 342-347.
2. Bowen C.R., Open J., Mahon S., Fitzmaurice J. Microstructural design of sensor materials using the core-shell concept] //J EUR CERAM. - 1999. - 19(2). P. 149-154 .

3. Goldstein A., Kravchik M. Sintering PZT-Powders in MW Furnace at $2.45 \mathrm{GHz}$. // Journal of the European Ceramic Society, 1999. - Vol. 19. - P. 989-992.

4. Agawal D. K. Microwave processing of ceramics // A review Solid State \& Mat. Sci. - 1998. - Vol. 3 (5). - P. 480486.

5. Fukushima H., Mori H., Hatanaka T., Matsui M. Properties and Microstuctures of PZT Ceramics Sintered by Microwave.] //Journal of the Ceramic Society of Japan. 1995. - Vol. 103. - P. 998-1003.

6. Сапунов В.В. Совершенствование технологии изготовления абразивного инструмента на бакелитовой связке с применением микроволнового излучения : дис. ... канд. техн. наук : 05.02 .07 : защищена 28.12.2015. - Ульяновск, 2015. - 221 с. - библиогр. 204219.

7. Microwave Solutions for Ceramic Engineers / Edited by D. E. Clark, D. C. Folz, C. E. Folgar, M. M. Mahmoud // New York: Wiley, 2005. - 494 pp.

8. Rao K. J., Vaidhyanathan B., Ganguli M., Ramakrishnan P.A. Synthesis of inorganic solids using microwaves // Chemistry of Materials. 1999. V. 11, No. 4. P. 882-895.

9. Makino Y., Ohmae T., Setsuhara Y. Sintering of Al203 - $\mathrm{ZrO}_{2}$ composites using millimeter-wave radiation // Key Engineering Materials. 1999. V. 161-163. P. 41-44.

10. Wil'ert-Porada M., Borchcrt R. Microwave sintering of metal-ceramic FGM // Functionally Graded Materials, edited by I. Shiota and Y. Miyamoto. Amsterdam: Elsevier, 1997. P. 349-354.

11. Gupta M., Wong Wai Leong E. Microwaves and Metals // Singapore: Wiley, 2007. - 228 pp.

12. Zhang S.-L., Buchta R., Sigurd D. Rapid thermal processing with microwave heating //Thin Solid Films. 1994. V. 246, No. 1/2. P. 151-157.

13. Lukas R. Mikrowelleunterstütze Wärmt- und Stoffübertragung beim Trocknen und Entbindern Technischer Keramik // Dissertation zur Erlagung des akademischen Grades Doktor-Ingenieur. Freibur, 2005. - 125 p.

14. Chandrasekaran S., Ramanathan S., Basak T. Microwave Material Processing-A Review // AIChE Journal. 2012. V. 58 P. 330-363.

15. Ванецев А. С. Спекание оксидных порошков с использованием микроволнового воздействия. - М.: МГУ, 2011. - 32 c.

16. Лыков А. В. Теория теплопроводности. - М.: Высшая школа. $-1967 .-600$ с.

Отримана в редакції 22.12.2016, прийнята до друку 07.02.2017 


\title{
Energy Efficiency of Technical Ceramic Sintering in Microwave Field
}

\author{
I. L. Boshkova ${ }^{1}$, N. V. Volgusheva ${ }^{2}$, N. A. Kolesnychenko ${ }^{3}$ \\ Odessa National Academy of Food Technologies, 112 Kanatnaia str., Odessa, 65039, Ukraine \\ e-mail: ${ }^{1}$ ira_boshkova@mail.ru, ${ }^{2}$ n-volgusheva@mail.ru, ${ }^{3}$ kolesnychenko.natalia@yandex.ua. \\ ORCID: ${ }^{1}$ http://orcid.org/0000-0001-5989-9223, ${ }^{2}$ http://orcid.org/0000-0002-9984-6502, ${ }^{3}$ http://orcid.org/0000-0002-7521-5191.
}

\begin{abstract}
Heating in the microwave field opens the possibility of developing fundamentally new technologies for creating materials that are significantly higher in comparison with existing operational and functional properties. High heating rates in the microwave field result in significant power savings and reduction in sintering time, which is important when creating high-quality materials. This method allows obtaining products with a finely dispersed and defect-free microstructure and, as a result, improved functional properties. The paper deals with the features of heating of dense materials used in the technical ceramics production, under the action of a microwave field. Silica carbide powders and alumina powders were used as the test material. The estimation of power efficiency of microwave sintering technology is presented on the example of ceramic substrates production. For evaluation, data on the technological parameters of sintering of silicon carbide in an oven by MARUWA and the values of the speed and duration of microwave heating were used. It is established that the intensity of sintering during the transition to microwave technology is significantly increased, while the power costs are significantly reduced.
\end{abstract}

Keywords: Microwave field; Energy efficiency; Sintering; Intensification; Ceramics.

\section{References}

1. Wielage, B., Krause, H., Leparoux, S. (2002) Sintern von Keramik in einem gasbeheizten Ofen mit Mikrowellenunterstützung. Gaswärme International. No. 51(8), 342-347.

2. Bowen, C.R. (1999) Microstructural design of sensor materials using the core-shell concept. Journal of the European Ceramic Society, 19(2), 149-154.

Doi: https://doi.org/10.1016/s0955-2219(98)00198-8

3. Goldstein, A., Kravchik, M. (1999) Sintering PZTPowders in MW Furnace at $2.45 \mathrm{GHz}$. Journal of the European Ceramic Society, Vol. 19, 989-992.

Doi: https://doi.org/10.1016/s0955-2219(98)00359-8

4. Agawal, D. K. (1998) Microwave processing of ceramics. A review Solid State \& Mat. Sci., 3(5), 480-485. Doi: https://doi.org/10.1016/s1359-0286(98)80011-9

5. Fukushima, H., Mori, H., Hatanaka, T., Matsui, M. (1995) Properties and Microstuctures of PZT Ceramics Sintered by Microwave. Journal of the Ceramic Society of Japan, Vol. 103, 1011-1016.

Doi: https://doi.org/10.2109/jcersj.103.1011

6. Sapunov. V. V. (2015) Sovershenstvovaniye tekhnologii izgotovleniya abrazivnogo instrumenta na bakelitovoy svyazke s primeneniyem mikrovolnovogo izlucheniya : dis. ... kand. tekhn. nauk : 05.02.07 : zashchishchena 28.12.2015. Ulianovsk, 221 p. bibliogr. 204-219 (in Russian).

7. Microwave Solutions for Ceramic Engineers (2005) Edited by D. E. Clark, D. C. Folz, C. E. Folgar, M. M. Mahmoud. New York: Wiley, 494 p.

8. Rao, K. J., Vaidhyanathan, B., Ganguli, M., Ramakrishnan, P.A. (1999) Synthesis of inorganic solids using microwaves. Chemistry of Materials, 11(4), 882-895.
Doi: https://doi.org/10.1021/cm9803859

9. Makino, Y., Ohmae, T., Setsuhara, Y. (1999) Sintering of $\mathrm{Al} 2 \mathrm{O} 3-\mathrm{ZrO}_{2}$ composites using millimeter-wave radiation. Key Engineering Materials, Vol.161-163, 41-44. Doi: https://doi.org/10.4028/www.scientific.net/kem.161-

163.41

10. Wil'ert-Porada, M., Borchert, R. (1997) Microwave sintering of metal-ceramic FGM. Functionally Graded Materials. Functionally Graded Materials 1996, 349-354. Doi: https://doi.org/10.1016/b978-044482548-3/50058-5

11. Gupta, M., Wong Wai Leong, E. (2007) Microwaves and Metals. Singapore: Wiley, 228 p. doi: https://doi.org/10.1002/9780470822746

12. Zhang, S.-L., Buchta, R., Sigurd, D. (1994). Rapid thermal processing with microwave heating. Thin Solid Films, Vol. 246, No. 1-2, 151-157.

13. Lukas R. (2005) Mikrowelleunterstütze Wärmt- und Stoffübertragung beim Trocknen und Entbindern Technischer Keramik. Dissertation zur Erlagung des akademischen Grades Doktor-Ingenieur. Freibur, 125 p.

14. Chandrasekaran S., Ramanathan S., Basak T. (2012) Microwave Material Processing - a Review. AlChE Journal, 58(2), 330-363. Doi: https://doi.org/10.1002/aic.12766_

15. Vanetsev A. S. (2011) Spekaniye oksidnykh poroshkov s ispolzovaniyem mikrovolnovogo vozdeystviya. M.: MGU, 32 p. (in Russian).

16. Lykov A. V. (1967). Teoriia teploprovodnosti. M.: Vysshaia shkola, 600 p. (in Russian).

Received 22 December 2016 Approved 07 February 2017 Available in Internet 17 March 2017 